University of Nebraska - Lincoln

DigitalCommons@University of Nebraska - Lincoln

Educational Psychology Papers and

Publications

Educational Psychology, Department of

2011

Child temperament, teacher-child interactions, and teacher-child relationships: A longitudinal investigation from first to third grade

Kathleen Moritz Rudasill

University of Nebraska-Lincoln, kmrudasill@vcu.edu

Follow this and additional works at: https://digitalcommons.unl.edu/edpsychpapers

Part of the Educational Psychology Commons

Rudasill, Kathleen Moritz, "Child temperament, teacher-child interactions, and teacher-child relationships: A longitudinal investigation from first to third grade" (2011). Educational Psychology Papers and Publications. 118.

https://digitalcommons.unl.edu/edpsychpapers/118

This Article is brought to you for free and open access by the Educational Psychology, Department of at DigitalCommons@University of Nebraska - Lincoln. It has been accepted for inclusion in Educational Psychology Papers and Publications by an authorized administrator of DigitalCommons@University of Nebraska - Lincoln. 


\title{
Child temperament, teacher-child interactions, and teacher-child relationships: A longitudinal investigation from first to third grade
}

\author{
Kathleen Moritz Rudasill \\ Department of Educational and Counseling Psychology, \\ College of Education and Human Development, University of Louisville, Louisville, KY 40292, USA
}

\begin{abstract}
The quality of children's relationships with teachers in early elementary grades has implications for their academic and behavioral outcomes in later grades (e.g., Hamre \& Pianta, 2001). The current study uses data from the NICHD SECCYD to extend work from a recent study of first grade (Rudasill \& Rimm-Kaufman, 2009) by examining connections between child shyness, effortful control, and gender and teacher-child relationship quality in third grade directly and indirectly through the frequency of teacher- and child-initiated interactions in third grade, and teacher-child relationship quality in first grade. Path analyses using structural equation models were used to test two different models, one for conflict and one for closeness. Findings reveal five main points: (a) Children's characteristics (i.e., shyness and effortful control) were related to the frequency of interactions they initiated with their third grade teachers; (b) The number of teacher-initiated interactions with a child in third grade was positively related to teacher perception of conflict, but not closeness, with that child; (c) Teachers' perceptions of relationship quality and the number of teacher-initiated interactions in first grade predicted teachers' perceptions of relationship quality and the number of teacher-initiated interactions in third grade; (d) Children's gender predicted the number of teacher-initiated interactions and teachers' perceptions of relationship quality in third grade; (e) Teacher-child relationship quality in first grade, and the number of teacher and child-initiated interactions in third grade, mediated associations between children's characteristics and teacher-child relationship quality in third grade. Findings have implications for future research and training for preservice and practicing teachers.
\end{abstract}

Keywords: teacher-child relationships, temperament, longitudinal, path analysis

Ample research supports the importance of positive teacher-child relationships for children's academic, social, and behavioral success in school, particularly for children at risk for school failure (Baker, 2006; Hamre and Pianta, 2001, 2005; O'Connor and McCartney, 2007). However, negative teacherchild relationships have been linked to children's poor school outcomes (Hamre and Pianta, 2001; Pianta et al., 1995). Given the critical role teacher-child relationships play in children's success in elementary school and beyond, it is important to investigate the mechanisms of early teacher-child relationship formation, and how those mechanisms extend to teacher-child relationship quality in later elementary grades.

Prior research indicates that characteristics and behaviors of both children and teachers impact teacher-child relationship quality (Baker, 2006; Eisenhower et al., 2007; Ewing and Taylor, 2009; Rudasill et al., 2006; Rydell et al., 2005; Saft and Pianta, 2001). Rudasill and Rimm-Kaufman (2009) examined associations between child characteristics (i.e., ratings of shyness and effortful control at approximately age $4 \frac{1}{2} 2$ years, and gender) and teacher-child relationship quality in first grade both directly and indirectly via the frequency of teacher- and child-initiated interactions between teachers and children in first grade. They found that children lower in shyness had higher teacher-child conflict and closeness ratings, children lower in effortful control had higher conflict ratings and children higher in effortful control had higher closeness ratings. In addition, children lower in shyness were more likely to initiate interactions with teachers, and more child-initiated interactions were related to more teacher-child closeness. They also found that teachers were more likely to rate their relationships as higher in conflict with boys and higher in closeness with girls. Conclusions from this study suggest that one mechanism for building positive relationships between teachers and children may be the frequency of interactions between them. The current study extends this work, examining connections between child shyness, effortful control, and gender and teacher-child relationship quality in third grade. In addition, this study examines the mediating roles of teacher-child relationship quality in first grade and teacher-child interactions in third grade on the associations between children's shyness, effortful control, gender, and relationship quality in third grade. 


\section{Theoretical framework}

This study is informed by the Transactional Model of Development (Sameroff and Fiese, 2000; Sameroff and MacKenzie, 2003), and the Ecological and Dynamic Model of Transition (Rimm-Kaufman \& Pianta, 2000). The Transactional Model conceptualizes individual development as emerging from bi-directional interactions between an individual and the environment, such that the individual affects the environment and the environment, in turn, affects the individual (Sameroff \& Fiese).

For children in school, teachers in the classroom provide the environment with which children have frequent interactions. These interactions are reciprocal (e.g., teacher behaviors influence child behaviors, and vice versa) and have implications for the quality of relationships children develop with their teachers (Sameroff \& MacKenzie, 2003). According to the Ecological and Dynamic Model of Transition (Rimm-Kaufman \& Pianta, 2000), children's bi-directional interactions with teachers are important for their successful transition to formal school. In addition, early teacher-child interactions have implications for children's later teacher-child interactions.

The Transactional Model of Development and the Ecological and Dynamic Model of Transition, together, provide a framework for understanding the influence of repeated, reciprocal interactions between children and teachers. This study examines direct relationships between children's characteristics and teacher-child relationship quality in third grade, as well as the mediating effects of earlier teacher-child relationship quality (first grade) and the number of concurrent teacher-child interactions (third grade). Indeed, research shows that early teacher-child relationship quality predicts later teacher-child relationship quality (Howes et al., 2000; O'Connor and McCartney, 2006), suggesting the stability of individual child characteristics contributes to the quality of teacher-child relationships across time, and that the nature of early teacher-child relationships may form a model for children about the way teacher-child relationships should and will be.

\section{Predictors of teacher-child relationship quality}

The quality of children's relationships with teachers is driven, in part, by characteristics of children, such as gender and temperament (Eisenhower et al., 2007; Hamre and Pianta, 2001; Ladd et al., 1999). Evidence suggests that teachers view their relationships with girls better than those with boys (Hamre \& Pianta; Saft and Pianta, 2001; Silver et al., 2005; Stuhlman and Pianta, 2001). Teachers report more conflict in their relationships with boys, and more closeness in their relationships with girls. Ewing and Taylor (2009) propose a gender role socialization perspective to explain this consistent finding. Girls' relationships with others tend to be more focused on intimacy and sharing, whereas boys' relationships tend to be more activity-oriented. Considering that most teachers in early elementary grades are female, these different relationship styles may explain why teachers perceive their relationships to be more harmonious (i.e., higher in closeness) with girls than with boys. Regarding temperament, an emerging body of work suggests that certain temperament characteristics, such as effortful control, may promote positive teacher-child relationships, while others, such as anger, may hinder them (Justice et al., 2008; Rudasill and Rimm-Kaufman, 2009; Rudasill et al., 2006; Rydell et al., 2005). The present study targets children's gender and temperament as predictors of teacher-child relationship quality.

\subsection{Temperament}

Temperament is an individual's biologically based style of responding to people, events, and situations. Although behavioral manifestations of temperament change with development (Rothbart and Bates, 2006; Thomas and Chess, 1977) and are influenced by forces in the environment (e.g., parenting behavior), temperament shows some stability in children at least through middle childhood (Kagan et al., 1988; Rimm-Kaufman and Kagan, 2005). Temperament is theorized to comprise two overarching systems: reactivity and regulation (Rothbart \& Bates). Reactivity refers to the nature and intensity of an individual's biological reaction to the environment (e.g., showing shy behavior around an unfamiliar adult). Regulation refers to the ability to modulate reactivity (e.g., maintaining eye contact when meeting a new person, resisting the urge to hit someone in anger). The present study includes examination of children's shyness (a reactive dimension of temperament) and effortful control (indicative of regulation).

\subsubsection{Shyness}

An individual's level of shyness refers to his or her tendency to withdraw from unfamiliar people or other environmental stimuli (Asendorpf and Meier, 1993; Rothbart and Bates, 2006). Where children high in shyness are reticent and even fearful in the face of unfamiliarity, children who are low in shyness are likely to be comfortable with novel people and situations (Caspi and Silva, 1995; Kagan et al., 1992; Rothbart et al., 2006). Shyness is conceptualized as a reactive element of temperament because research has linked high reactivity in infancy to shyness in childhood (Kagan and Fox, 2006; Kagan et al., 1992, 1998).

Recent research indicates that higher shyness may hinder young children's abilities to form relationships (both positive and negative) with their teachers. Rudasill and RimmKaufman (2009) as well as Rydell et al. (2005) found that children's higher shyness was related to less closeness and less conflict with their teachers. Children low in shyness, on the other hand, had more closeness and more conflict with their teachers. In addition, Justice et al. (2008) found that preschoolers who were higher in shyness had less close relationships with their teachers. It could be that shyer children are less likely to form relationships with their teachers because they are disinclined to initiate or encourage interactions with their teachers. In support of this, Rudasill and Rimm-Kaufman found that shyer children initiated fewer interactions with their first grade teachers. Similarly, Coplan and Prakash (2003) examined teachers' interactions with children in preschool and found that shyer children initiated fewer interactions with their teachers, but received more interactions from teachers, than their peers who were lower in shyness. These studies point to higher shyness as a relationship suppressor; likewise, lower levels of shyness may promote children's relationship building, be it positive or negative.

\subsubsection{Effortful control}

Effortful control is the ability to activate an appropriate response (e.g., keeping your hands to yourself) in a situation where an inappropriate response is desired (e.g., taking another child's toy). The temperament dimensions of inhibitory control (the ability to inhibit a behavioral response) and attentional focusing (the ability to focus and sustain attention) have been identified as components of effortful control (Posner and Rothbart, 2000; Rothbart and Bates, 2006). 
Effortful control is particularly important for children's ability to form positive relationships (Rothbart \& Bates, 2006). Children with low levels of effortful control display more externalizing or acting out behaviors than their more regulated peers, whereas children who are higher in effortful control display fewer externalizing behaviors (Olson et al., 2005; Rothbart and Bates, 2006; Rothbart et al., 1994; Zhou et al., 2007). In addition, Rudasill and Rimm-Kaufman (2009) found that lower effortful control was linked to more teacher-child conflict in first grade. So effortful control appears to facilitate children's positive behaviors, resulting in higher quality teacher-child relationships.

\subsection{Teacher- and child-initiated interactions}

Emerging evidence suggests that children's shyness and effortful control are related to the frequency of their interactions with teachers (Coplan and Prakash, 2003; Keogh, 2003; Rudasill and Rimm-Kaufman, 2009). Coplan and Prakash found preschool teachers are more likely to initiate interactions with shyer children than those who were less shy. Rudasill and RimmKaufman's study with first grade students suggested that shyer children initiate fewer interactions with teachers, and children lower in effortful control receive more teacher-initiated interactions, such as behavioral corrections or admonitions.

The theoretical underpinnings of this study (RimmKaufman and Pianta, 2000; Sameroff and MacKenzie, 2003) also point to a bi-directional relationship between teacherand child-initiated interactions. Rudasill and Rimm-Kaufman (2009) found that more child-initiated interactions were associated with more teacher-initiated interactions, but more teacher-initiated interactions were associated with fewer childinitiated interactions. This finding may have been an artifact of the nature of teacher-initiated vs. child-initiated interactions. Child-initiated interactions were defined as instances where a child volunteered to help the teacher, asked for assistance, or engaged the teacher in social conversation. Teacher-initiated interactions were defined as one-on-one interactions between the teacher and child for at least $5 \mathrm{~s}$. The composition of these definitions suggests that child-initiated interactions may have included more positive interactions than teacher-initiated interactions. Further, Rudasill and Rimm-Kaufman's findings suggest that shyer children may have difficulty forming close relationships with teachers because they are unlikely to initiate interactions with their teachers. Similarly, children lower in effortful control may have more conflict with their teachers because their less regulated behavior makes them more likely to receive teacher-initiated interactions such as behavioral corrections or admonitions. A focus of the current study is to extend these findings by including teacher- and child-initiated interactions in third grade, thus enabling examination of bi-directional associations longitudinally (from first to third grade).

Theory (Rimm-Kaufman and Pianta, 2000; Sameroff and Fiese, 2000) and findings from the previous study (Rudasill \& Rimm-Kaufman, 2009) point to hypotheses about how child characteristics, teacher-child interactions, and prior teacherchild relationship quality relate to teachers' perceptions of the quality of their relationships with children in third grade (see Figure 1). First, it is expected that child characteristics will be related to the frequency of child-initiated interactions. This is based on findings from the previous study where children's lower levels of effortful control and lower shyness predicted more instances in which they initiated interactions with their teachers in first grade. The hypothesized model includes paths between children's characteristics and child-initiated interactions in third grade. Similarly, it is likely that a teacher's behavior toward a child will be related to his or her perceptions of the quality of the teacher-child relationship. The hypothesized model includes paths between teacher-initiated interactions in third grade and teacher-child conflict (or closeness) in third grade.

Second, consistent with the Ecological and Dynamic Model of Transition (Rimm-Kaufman \& Pianta, 2000) and previous research (e.g., O'Connor \& McCartney, 2006), children's interactions and relationships with teachers in first grade will be positively associated with their interactions and relationships with teachers in third grade. Paths were drawn between first and third grade child-initiated interactions, first and third grade teacherinitiated interactions, and first and third grade teacher-child conflict (or closeness). It is also expected that first grade teacherchild relationship quality will mediate associations between children's characteristics and third grade teacher-child relationship quality, so this was examined with mediation analyses.

Third, congruent with findings from the previous study in first grade (Rudasill \& Rimm-Kaufman, 2009) and the Transactional Model of Development (Sameroff and Fiese, 2000; Sameroff and MacKenzie, 2003) where development is posited to emerge from bi-directional interactions between an individual and the environment, it is hypothesized that children's characteristics and behaviors will be associated with teachers' behaviors and perceptions, and teachers' behaviors will be associated with children's behaviors. Findings from first grade showed that children's lower effortful control was related to more teacher-initiated interactions, and the frequency of child-initiated interactions and teacher-initiated interactions were related to each other. Thus, the current model includes paths from effortful control to third grade teacher-initiated interactions, with lower levels of effortful control predicted to be related to more teacher-initiated interactions. Associations between other child characteristics (i.e., shyness, gender) and teacher-initiated interactions were also included for exploratory purposes. In addition, paths from child-initiated interactions to teacher-initiated interactions both within and across grades were drawn, with relationships from first to third grade and within third grade expected to be consistent with those found in the previous study within first grade (i.e., more teacher-initiated interactions will be associated with more child-initiated interactions; more childinitiated interactions will be associated with fewer teacher-initiated interactions). Finally, the Transactional Model suggests that child and teacher-initiated interactions in third grade will mediate the associations between child characteristics and teacher-child relationship quality in third grade, so this was examined with mediation analyses.

\section{Method}

\subsection{Participants}

Children and their first and third grade teachers from the National Institute of Child Health and Human Development Study of Early Child Care and Youth Development (NICHD SECCYD) were participants in the present study. The NICHD SECCYD drew participants from women giving birth in 1991 in hospitals in 10 cities in the U.S. ( $N=8986$ mothers). From those who met eligibility requirements and agreed to be contacted by researchers $(N=5416), 1364$ mother-child pairs were randomly selected to be in the study. Data for the current study were collected in phase II, when study children were from preschool age (approximately 41/2 years) through first grade $(N=1226$ at the start of Phase II), and phase III, when study children were from 2 nd through 6 th grades $(N=1100$ at the start of phase III). The sample for the current study included all children who were still involved in the NICHD SECCYD in third grade $(N=994)$. One-way analyses of variance indicated that children still involved in the NICHD SEC- 
Figure 1. Hypothesized model. This figure shows hypothesized longitudinal relationships between child characteristics, teacher-child interactions, and teacher-child relationship quality. Original model (-): Significant paths from Rudasill and RimmKaufman (2009) study. Hypothesis 1 $(\cdots)$ : Children's characteristics will be related to their behavior; teacher behavior will be associated with teacher perceptions. Hypothesis 2 (- - ): Teacher-child interactions and relationship quality will be similar across grades one and three. Hypothesis $3(-\cdot-)$ : Child characteristics will be associated with teacher behavior/ perceptions; teacher behavior/perceptions will be associated with child behavior (transactional model).

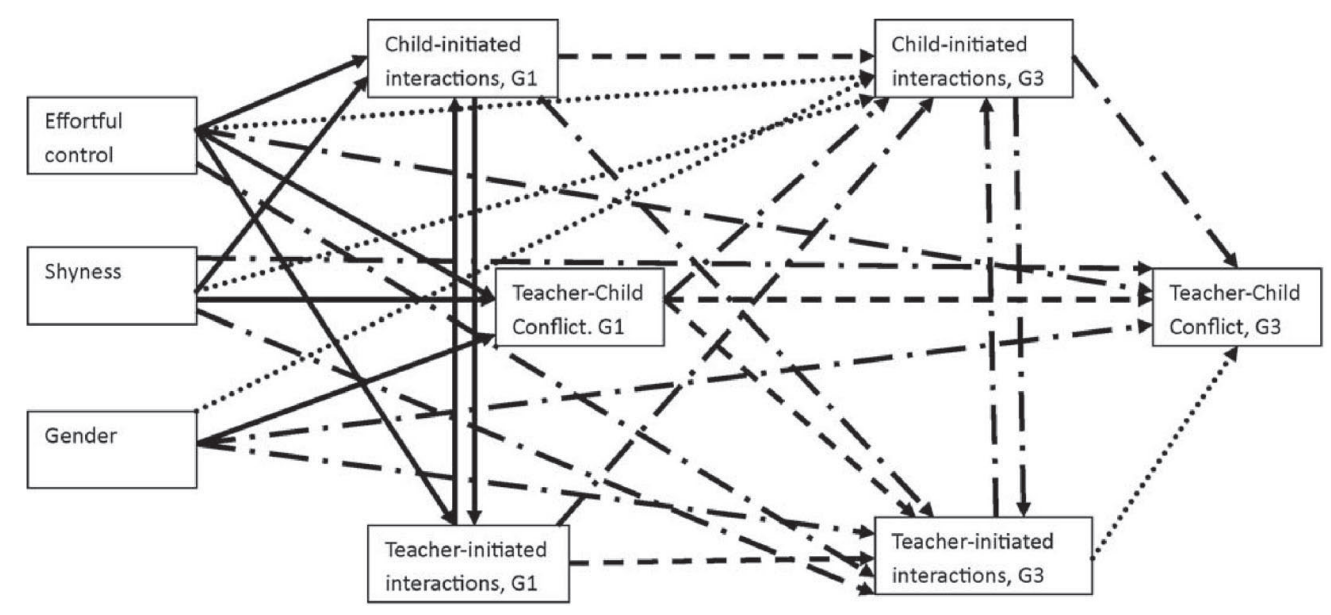

CYD in third grade were statistically different from those who were not $(n=370)$. In terms of gender $[F(1,1362)=5.816$, $p=.016$, partial $\left.\eta^{2}=.004\right]$, the sample in third grade had a lower percentage of boys $(50 \%)$ than the group of children who did not remain in the study $(57 \%)$. For race/ethnicity $[F$ $(1,1362)=7.388, p=.007$, partial $\left.\eta^{2}=.005\right]$, the third grade sample comprised a higher percentage of white students (82\%) than the group of children who did not remain in the study $(76 \%)$. Regarding maternal education $[F(1,1362)=27.054$, $p<.001$, partial $\left.\eta^{2}=.019\right]$, those in the study in third grade had mothers with higher levels of education $(M=14.45$ years $)$ than those who did not remain in the study $(M=13.66)$.

There were slightly more girls $(n=500)$ than boys $(n=494)$ in the third grade sample. Eighty-two percent of the study children were White $(n=817), 11 \%$ were Black or African American $(n=112), 7 \%(n=65)$ comprised American Indian, Eskimo, or Aleut, Asian or Pacific Islander, or Other. When children were in first grade, total annual family income ranged from $\$ 2,500$ (1\% of the sample) to $\$ 300,001$ (1\% of the sample). Mean income was $\$ 66,450(S D=\$ 50,907)$. Total annual family income when children were in third grade ranged from $\$ 2500$ ( $<1 \%$ of the sample) to $\$ 500,000$ ( $<1 \%$ of the sample). Mean income was $\$ 77,008(S D=\$ 68,273)$.

Teachers became involved in the study if they had study children in their classes. For the NICHD SECCYD, there was typically one child per classroom. However, for first grade there were 57 cases in which two study children were in a classroom, and eight cases in which there were three or more study children in a classroom. For third grade, there were 46 cases in which two study children were in a classroom, and nine cases in which there were three or more study children in a classroom.

First grade teachers had an average of 14.2 years of teaching experience $(S D=9.4)$ and were overwhelmingly female $(96 \%)$. The majority were White (94\%), and 3.5\% were Black/African American, $1.0 \%$ were Asian/Pacific Islander, .07\% were Latino, and $.08 \%$ were other ethnic/racial groups. Third grade teachers had an average of 11.85 years of teaching experience $(S D=10.53)$. The majority were White $(92 \%)$, and $3.5 \%$ were Black/African American, 1.6\% were Asian/Pacific Islander, $2.5 \%$ were Latino, and $0.04 \%$ were other ethnic/racial groups. Data on gender for third grade teachers were not available.

\subsection{Procedures}

Data for the current study were gathered when children were preschool age, and again in first and third grades. Data from the first time point were obtained from mothers during a laboratory visit. Data from first and third grade time points were obtained via observations of classrooms and from surveys distributed to teachers in the spring of each school year. More detail on the NICHD SECCYD may be found on the web at https://secc.rti.org.

\subsection{Measures}

\subsubsection{Children's temperament}

As part of the NICHD SECCYD, mothers assessed their children's temperament when children were preschool age using an abbreviated version of the Children's Behavior Questionnaire (CBQ; Rothbart et al., 1994). This instrument measures temperament in children ages 3-8 years via parent report of children's behaviors during the previous 6 months. The CBQ employs a Likert-style scale, where 1 = extremely untrue, and $7=$ extremely true. Although parent responses on eight subscales were gathered for the NICHD SECCYD, data from three subscales were used as measures of children's Shyness (Shyness subscale) and Effortful Control (Inhibitory Control and Attentional Focusing subscales).

The Shyness subscale is made up of 10 items where a higher score indicates more shyness. Sample items include "Sometimes seems nervous when talking to adults s/ he has just met" and "Acts shy around new people." Internal consistency for the shyness subscale with the current sample $(a=.87)$ was consistent with Cronbach alpha values found with other populations (Rothbart, Ahadi, Hershey, \& Fisher, 2001).

As was done in Rudasill and Rimm-Kaufman's (2009) study, as well as other studies (e.g., Olson et al., 2005), children's scores for Inhibitory Control and Attentional Focusing subscales were averaged to produce a measure of Effortful Control. The Inhibitory Control subscale is designed to measure the extent to which a child is able to inhibit inappropriate behaviors and demonstrate the ability to follow directions. Sample items include, "Can easily stop an activity when s/he is told 'no"' and "Has difficulty waiting in line for something (reversed)." The Attentional Focusing subscale is designed to measure a child's ability to focus and sustain attention, as needed. Sample items include, "Has a hard time concentrating on an activity when there are distracting noises (reversed)" and "When building or putting something together, becomes very involved in what s/he is doing, and works for long periods." Internal consistency for the Inhibitory Control and Attentional Focusing subscales with the current sample $\left(\alpha^{\prime} s=.74\right)$ were consistent with those found in other samples (Rothbart et al., 2001). Cronbach's alpha for Inhibitory Control and Attentional Focusing subscales together was .84 . 
Table1.Means, standard deviations, ranges, and correlation coefficients for child attributes, teacher-child relationships, and teacher-child interactions.

\begin{tabular}{|c|c|c|c|c|c|c|c|c|c|c|c|c|c|}
\hline Variable & $M$ & $S D$ & Range & 1 & 2 & 3 & 4 & 5 & 6 & 7 & 8 & 9 & 10 \\
\hline 1. Effortful control & 4.7 & 0.72 & $2.3-6.4$ & - & & & & & & & & & \\
\hline 2. Shyness & 3.5 & 1.1 & $1.0-6.6$ & .02 & - & & & & & & & & \\
\hline \multicolumn{14}{|l|}{ Teacher-child relationships } \\
\hline 4. Conflict G1 & 10.9 & 5.2 & $7.0-35.0$ & $-.27^{*}$ & $-.13^{*}$ & $-.17^{*}$ & - & & & & & & \\
\hline 5. Closeness G1 & 34.0 & 5.0 & $16.0-40.0$ & $.10^{*}$ & $-.10^{*}$ & $.14^{*}$ & $-.28^{*}$ & - & & & & & \\
\hline \multicolumn{14}{|c|}{ Teacher-child interactions } \\
\hline 8. Teacher-initiated G1 & 4.8 & 4.6 & $0-50.0$ & $-.16^{*}$ & $-.11^{*}$ & -.04 & $.10^{*}$ & -.05 & $.17^{*}$ & -.01 & - & & \\
\hline 9. Child-initiated G1 & 4.6 & 3.9 & $0-25.0$ & .00 & $-.10^{*}$ & .02 & .04 & $.12^{*}$ & .05 & $.08^{*}$ & $.08^{*}$ & - & \\
\hline 10. Teacher-initiated G3 & 6.6 & 4.6 & $0-42.8$ & $-.20^{*}$ & $-.10^{*}$ & $-.12^{*}$ & $.19^{*}$ & -.05 & $.28^{*}$ & .01 & $.32 *$ & .00 & - \\
\hline 11. Child-initiated G3 & 2.2 & 1.8 & $0-12.0$ & .01 & $-.10^{*}$ & .05 & .03 & $.12^{*}$ & .04 & $.19^{*}$ & .03 & $.14^{*}$ & $.27^{*}$ \\
\hline
\end{tabular}

Gender: 0 = boy, 1 = girl.

$* p<.05$

\subsubsection{Teacher-child interactions}

The NICHD SECCYD data collection included observations of time-sampled, behavioral frequencies in first and third grade classrooms. Eight 10-min cycles of observations of behavioral frequencies were conducted in one day; each minute comprised 30 s of observation, followed by 30 s of recording. During each 30-s segment of an observation cycle, observers noted the presence of a teacher or child behavior, such as interacts with the study child (teacher behavior) or requests help from teacher (child behavior). Observers were trained using videotapes and a manual, and had to achieve $60 \%$ reliability with a master coder prior to conducting observations. Live reliability between two observers for a subsample was estimated using Pearson correlations. For first grade observations, live reliability for behavioral codes used in the current study ranged from .85 to .98 . For third grade observations, live reliability for behavioral codes used in the current study ranged from .82 to .95 .

Similar, but not identical, observational data were collected in first and third grades. For first grade, the frequency of Teacher-Initiated Interactions with each study child was the total number of times the teacher interacted one-on-one with the study child for $5 \mathrm{~s}$ or more (see Rudasill \& Rimm-Kaufman, 2009, for more information). Examples of Teacher-Initiated Interactions were questions for the study child, listening to the study child's reading, talking with the study child about class work, or talking to the study child about disciplinary issues. For third grade, the number of Teacher-Initiated Interactions with the study child was calculated by adding the number of times during the observation cycles that the teacher was observed to attend to the study child in some way (unlike first grade, there was not a time requirement for the duration of these interactions). This comprised intentional verbal or nonverbal interactions initiated by the teacher and received by the study child, and included academic, social, or disciplinary interactions directed to the study child. This value was used to assess Teacher-Initiated Interactions for third grade because it most closely represented the nature of one-on-one interactions between child and teacher captured for first grade.

The frequency of Child-Initiated Interactions in both first and third grades was the total number of times the child requested help from the teacher and volunteered to help the teacher. This deviates slightly from procedures used by Rudasill and RimmKaufman (2009) where Child-Initiated Interactions in first grade also included the number of times the child-initiated social interaction with the teacher. Because this frequency was not available for third grade, it was removed from first grade in this study to keep Child-Initiated Interactions similar in both years.

\subsubsection{Teacher-child relationship quality}

First and third grade teachers in the NICHD SECCYD reported on the quality of their relationships with children using the short form of the Student-Teacher Relationship Scale (STRS; Pianta, 2001). The short version of the STRS is designed to measure teachers' perceptions of the extent to which their relationships with children are Conflictual and Close (15 items). The Conflict subscale has eight items, such as "Dealing with this child drains my energy" and "This child and I always seem to be struggling with each other." The Closeness subscale has seven items; sample items include "I share an affectionate, warm relationship with this child" and "It is easy to be in tune with what this child is feeling." The STRS employs a 5-point Likert-type response scale $(1=$ definitely does NOT apply, 5 = definitely applies). Internal consistency estimates for STRS ratings by first grade teachers (Conflict $=.84$, Closeness $=.64$ ) were lower than those by third grade teachers $($ Conflict $=.89$, Closeness $=.86$ ). The internal consistency for Closeness in first grade is lower than acceptable by convention, and should be interpreted with caution.

\section{Results}

\subsection{Descriptive analyses}

Descriptive analyses of scores for temperament, teacherchild interactions, and teacher-child relationships were examined. Means, standard deviations, and bivariate correlations are displayed in Table 1. Tests of skewness and kurtosis were non-significant for all variables. T-tests indicated that teacher-child Conflict scores in first $(M=10.9, S D=5.2)$ and third $(M=11.6, S D=6.0)$ grades were statistically different $(t=-2.41, d f=733, p=.016$, Cohen's $d=-.13)$, as were Closeness scores in first $(M=34.0, S D=5.0)$ and third $(M=33.1$, $S D=5.2)$ grades $(t=4.10, d f=732, p<.001$, Cohen's $d=.17)$. The mean of Child-Initiated Interactions in first grade $(M=4.56, S D=3.87)$ was higher than the mean for Child-Initiated Interactions in third grade $(M=2.23, S D=1.83)$, and these scores were statistically different $(t=17.502, d f=873$, $p<.001$, Cohen's $d=.77$ ). The range of the number of ChildInitiated Interactions in first grade (range $=0-25$ ) was larger than in third grade (range $=0-12$ ). The means for the number of Teacher-Initiated Interactions in first $(M=4.80, S D=4.63)$ and third grades $(M=6.6, S D=4.63)$ were also statistically different $(t=9.99, d f=873, p<.001$, Cohen's $d=-.39)$. Frequencies of Teacher-Initiated Interactions were calculated slightly differently in first and third grade due to changes in data col- 
Figure 2. Predicting teacherchild (a) conflict and (b) closeness. This figure displays standardized coefficients for statistically significant paths between child characteristics, teacher-child interactions, and teacher-child relationship quality.
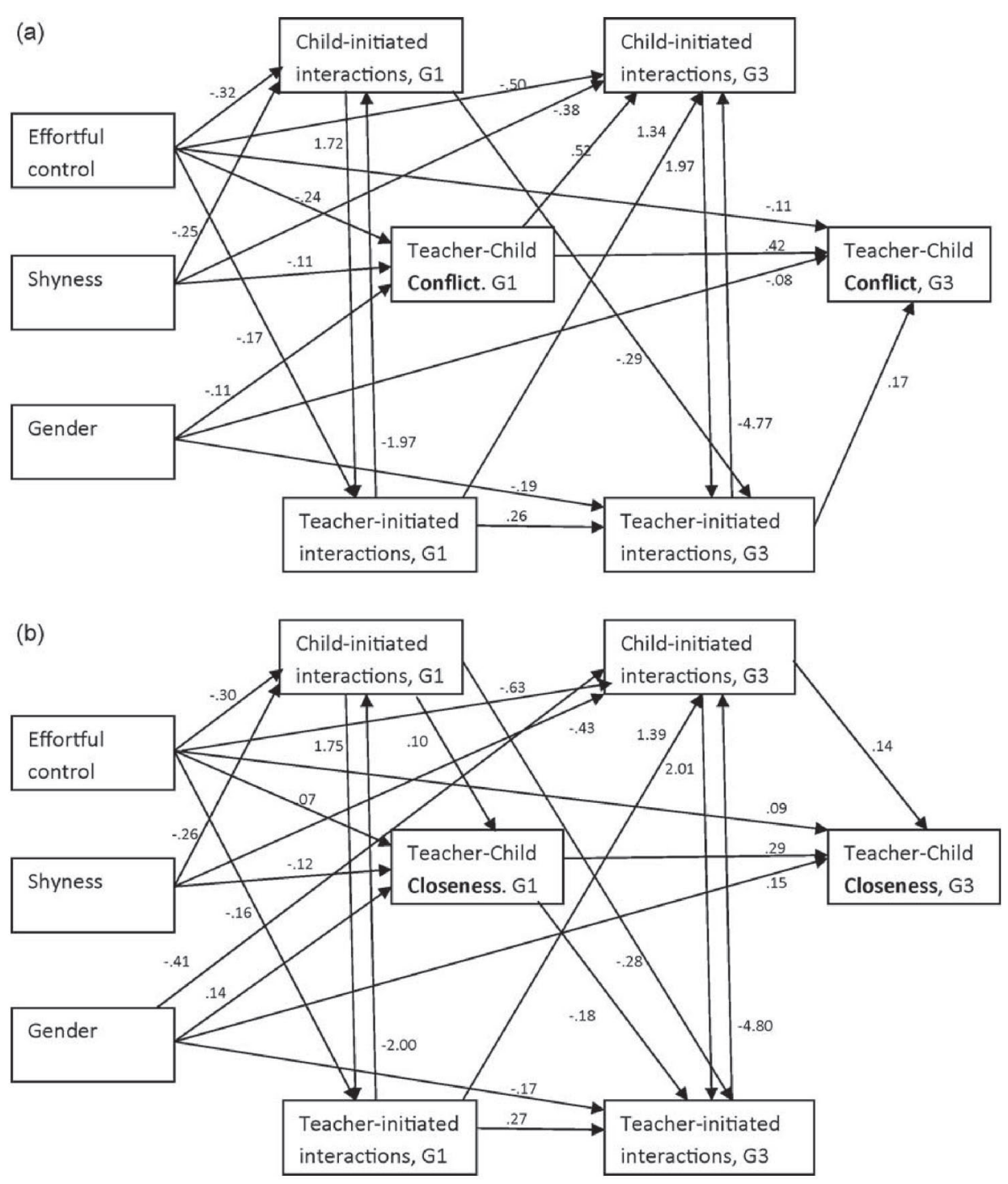

lection within the NICHD SECCYD, so statistical tests of differences should be interpreted with caution.

Correlational analyses revealed that scores for most variables were not highly correlated (i.e., less than .3). However, Teacher-Initiated Interactions in first and third grades were moderately correlated $(r=.32, p<.01)$, as were teacher-child Conflict in first and third grades $(r=.49, p<.01)$, teacher-child Closeness in first and third grades $(r=.34, p<.01)$, and teacherchild Conflict and Closeness in third grade $(r=-.38, p<.01)$.

\subsection{Data analyses}

Data were analyzed with path analyses using structural equation modeling. Models allowed for estimates of direct associations between gender, shyness, and effortful control and first and third grade teacher-child Conflict and Closeness. The models allowed for estimates of indirect associations between child characteristics and teacher-child relationship quality through first grade teacher-child relationship quality and third grade teacher-child interactions. Refer to Figure 1 for the hypothesized model. To test for mediation, confidence intervals for the distribution of the products of the indirect effects were calculated using PRODCLIN (MacKinnon, Fritz, Williams, \& Lockwood, 2007). The following fit indices were used to evaluate fit between the data and the models: comparative fit index (CFI),
Tucker-Lewis Index (TLI), non-linear index (NLI) (values close to 1 indicate good fit), and RMSEA (values less than .06 indicate good fit) (Fan et al., 1999; Hu and Bentler, 1999).

\subsection{Teacher-child conflict model}

Figure 2 shows statistically significant paths (with standardized coefficients) that resulted from analysis with teacherchild Conflict in first and third grades. Fit indices suggest good fit $\left(\chi^{2}=7.936_{5}, p=.16\right.$; NFI = .99; TLI = 0.96; CFI = 1.0; RMSEA $=.02$ ).

\subsubsection{Direct associations with conflict}

Results show that children lower in shyness $(\beta=-0.11$, $p=.001)$, lower in effortful control $(\beta=-0.24, p<.001)$, and boys $(\beta=-0.11, p=.001)$ were likely to have more Conflict in their relationships with first grade teachers. Similarly, children with lower effortful control $(\beta=-0.11, p<.001)$ and boys $(\beta=-0.08$, $p=.015)$ were more likely to be rated by third grade teachers as having Conflictual relationships. Child-initiated and TeacherInitiated Interactions were not directly associated with teacherchild Conflict in first grade. Teacher-child Conflict in first grade predicted Conflict in third grade $(\beta=0.42, p<.001)$, and Teacher-Initiated Interactions in third grade were positively related to Conflict in third grade $(\beta=0.17, p<.001)$. 


\subsubsection{Direct associations with teacher-child interactions}

Shyer children initiated fewer interactions with teachers in first grade $(\beta=-0.25, p=.002)$ and third grade $(\beta=-0.38$, $p=.038)$. Children lower in effortful control initiated more interactions with teachers in first $(\beta=-0.32, p<.001)$ and third grade $(\beta=-0.50, p=.011)$, and received more Teacher-Initiated Interactions in first grade $(\beta=-0.17, p=.014)$. Boys were more likely than girls to receive teacher-initiated interactions in third grade $(\beta=-0.19, p=.01)$. Child-Initiated Interactions in first grade were negatively associated with Teacher-Initiated Interactions in third grade $(\beta=-0.29, p<.001)$, and Teacher-Initiated Interactions in first grade were positively related to Teacher-Initiated $(\beta=0.26, p<.001)$ and Child-Initiated $(\beta=1.35, p<.001)$ Interactions in third grade. For both first and third grade, more Child-Initiated Interactions were associated with more TeacherInitiated Interactions $(\beta=1.72, p<.001$ for first grade, $\beta=1.97$, $p<.001$ for third grade), but more Teacher-Initiated Interactions predicted fewer Child-Initiated Interactions $(\beta=-1.97, p<.001$ for first grade, $\beta=-4.77, p<.001$ for third grade). Finally, first grade Conflict positively predicted third grade Child-Initiated Interactions $(\beta=0.52, p=.007)$.

\subsubsection{Tests for mediation}

Confidence intervals of the products of indirect effects were calculated to test for the mediating roles of teacher-child Conflict in first grade on the relationships between child characteristics (effortful control and gender) and teacher-child Conflict in third grade, and to test the mediating role of Teacher-Initiated Interactions on the relationship between child gender and teacher-child Conflict in third grade (MacKinnon et al., 2007). All tests for mediation were statistically significant. Lower and upper limits of confidence intervals set at $95 \%$ for the mediating roles of teacher-child Conflict in first grade on the association between effortful control and teacher-child Conflict in third grade (lower $=-1.13$, upper $=-.60$ ), and on the association between gender and teacher-child Conflict in third grade (lower $=-.91$, upper $=-.23$ ) did not include zero, indicating that teacher-child Conflict in first grade mediated these relationships. The lower and upper limit of the confidence interval for the mediating role of Teacher-Initiated Interactions in third grade on the association between gender and teacherchild Conflict in third grade (lower $=-.69$, upper $=-.09$ ) also did not include zero, indicating that Teacher-Initiated Interactions in third grade mediated this association.

\subsection{Teacher-child closeness model}

The path analysis model testing whether children's temperament and gender were directly and indirectly associated with teacher-child Closeness in first and third grade through Teacher- and Child-Initiated Interactions in first and third grade appears in Figure 2 with standardized coefficients. Fit indices suggest good fit $\left(\chi^{2}=4.488_{5}, p=.48\right.$; NFI = .99; $\mathrm{TLI}=1.01 ; \mathrm{CFI}=1.0 ; \mathrm{RMSEA}=.00$ ).

\subsubsection{Direct associations with closeness}

Results from the path analysis indicate that children with lower shyness $(\beta=-0.12, p<.001)$, higher effortful control $(\beta=0.07, p=.044)$, and girls $(\beta=0.14, p<.001)$ were more likely to have Close relationships with first grade teachers. Similarly, children with higher effortful control $(\beta=0.09$, $p=.007)$ and girls $(\beta=0.15, p<.001)$ were more likely to be rated by third grade teachers as having Close teacher-Child relationships. Child-Initiated Interactions in first grade were positively associated with Teacher-Child Closeness in first grade $(\beta=0.10, p=.002)$. Teacher-child Closeness in first grade predicted Closeness in third grade $(\beta=0.29, p<.001)$. Finally, Child-Initiated Interactions in third grade were positively related to Closeness in third grade $(\beta=0.14, p<.001)$.

\subsubsection{Direct associations with teacher-child interactions}

Shyer children initiated fewer interactions with teachers in first grade $(\beta=-0.26, p=.002)$ and third grade $(\beta=-0.43$, $p=.021)$. Those lower in effortful control initiated more interactions with teachers in first $(\beta=-0.30, p<.001)$ and third grades $(\beta=-0.63, p=.001)$, and received more Teacher-Initiated Interactions in first grade $(\beta=-0.16, p=.023)$. Boys were more likely than girls to initiate interactions with teachers $(\beta=-0.41, p=.032)$ and receive interactions from teachers $(\beta=-0.17, p=.018)$ in third grade. Child-Initiated Interactions in first grade were negatively associated with Teacher-Initiated Interactions in third grade $(\beta=-0.28, p<.001)$, and Teacher-Initiated Interactions in first grade were positively related to Teacher-Initiated $(\beta=0.27, p<.001)$ and Child-Initiated $(\beta=1.39, p<.001)$ Interactions in third grade. For both first and third grade, more Child-Initiated Interactions were associated with more Teacher-Initiated Interactions $(\beta=1.747$, $p<.001$ for first grade, $\beta=2.006, p<.001$ for third grade), but more Teacher-Initiated Interactions predicted fewer ChildInitiated Interactions $(\beta=-2.001, p<.001$ for first grade, $\beta=-4.802, p<.001$ for third grade). Teacher-child Closeness in first grade was negatively related to Teacher-Initiated Interactions in third grade $(\beta=-0.18, p=.018)$.

\subsubsection{Tests for mediation}

Confidence intervals of the products of indirect effects were calculated to test for the mediating role of teacher-child Closeness in first grade on the relationship between gender and teacher-child Closeness in third grade, and the mediating role of Child-Initiated Interactions in third grade on the relationships between child characteristics (effortful control and gender) and teacher-child Closeness in third grade (MacKinnon et al., 2007). All tests for mediation were statistically significant. Lower and upper limits of confidence intervals set at $95 \%$ for the mediating roles of teacher-child Closeness in first grade on the association between gender and teacher-child Closeness in third grade (lower $=.19769$, upper $=.64462$ ) did not include zero, indicating that previous teacher-child Closeness (first grade) mediated this relationship. Lower and upper limits of confidence intervals set at 95\% for the mediating roles of Child-Initiated Interactions in third grade on the association between effortful control and teacher-child Closeness in third grade (lower $=-1.11$, upper $=-.20$ ), and on the association between gender and teacherchild Closeness in third grade (lower $=-1.17$, upper $=-.05$ ) did not include zero, indicating that Child-Initiated Interactions in third grade mediated these relationships.

\section{Discussion}

This paper describes an examination of associations between children's temperament at preschool age (approximately $4 \frac{1}{2}$ years old), teacher-child interactions and relationships in first grade, and teacher-child interactions and relationships in third grade. Main findings will be discussed according to the hypotheses addressed in this study.

\subsection{Hypothesis 1}

As expected, children's gender and early temperament ratings predicted the frequency of interactions they initiated with their third grade teachers. Children with lower levels of both effortful control and shyness were more likely to initiate inter- 
actions with third grade teachers in the teacher-child conflict and closeness models, and boys were more likely to initiate interactions with third grade teachers in the closeness model. Findings regarding effortful control and shyness were congruent with those from Rudasill and Rimm-Kaufman's (2009) study with this population in first grade, as well as other research (e.g., Coplan and Prakash, 2003; Kagan et al., 1988). Coplan and Prakash found that children who displayed behaviors indicative of lower effortful control and lower shyness (e.g., more aggressive) were more likely to initiate interactions with their teachers. In contrast, research shows that a marker of higher shyness is the reluctance to engage in interactions with others (e.g., Asendorpf \& Meier, 1993; Kagan et al.).

The fact that boys were more likely to initiate interactions with third grade teachers in the current study lends further support to a substantial body of literature linking student gender to the frequency of interactions between students and teachers. Research indicates that boys are more likely to dominate classroom processes, in part, because of their greater tendency to initiate interactions with teachers (Drudy and Chatain, 2002; She, 2000; Smith et al., 2007).

The frequency with which a teacher-initiated interactions with a child in third grade was related to the teacher's perception of conflict, but not closeness, with that child. This is consistent with work linking teachers' behavior with their perceptions of children. Stuhlman and Pianta (2001) examined relationships between kindergarten and first grade teachers' narrative descriptions of children and their behaviors toward those children. They found that more negative affect in a teacher's narrative about a child was related to more frequent interactions with that child, and concluded that teachers' perceptions of children are closely tied to their behaviors toward those children. Similarly, in Thijs, Koomen, and Van der Leij's (2008) study of kindergarten teachers' perceptions and behaviors toward children, findings suggest that teachers provide more behavior regulation and socioemotional support for students with whom they perceive a negative relationship. This suggests that teachers are more likely to initiate interactions with students they perceive more negatively, and findings from the current study bear this out.

\subsection{Hypothesis 2}

As expected, teacher-child relationship quality in first grade predicted teacher-child relationship quality in third grade, and teacher-initiated interactions in first grade predicted teacher-initiated interactions in third grade. However, there was no longitudinal association between child-initiated interactions in first and third grades. These findings, with the exception of those related to child-initiated interactions, are consistent with the Dynamic and Transactional Model (RimmKaufman \& Pianta, 2000) which posits that early teacher-child interactions predict later interactions, as well as empirical work showing similarity between different teachers' ratings of conflict and closeness with the same student from preschool to early elementary or across early elementary grades (Howes et al., 2000; O'Connor and McCartney, 2006; Pianta et al., 1995). Findings from this study extend support for the idea that children's early relationships and interactions help establish trajectories for children's later relationships and interactions.

\subsection{Hypothesis 3}

Compatible with theoretical work implicating bi-directional processes between children and teachers in elementary school (Rimm-Kaufman \& Pianta, 2000), results suggest that children's characteristics contribute to teachers' behaviors and perceptions, and teachers' behaviors contribute to children's behaviors. Children's effortful control and gender were re- lated to teacher-child relationship quality in third grade; these findings support those from the Rudasill and Rimm-Kaufman (2009) study and other empirical work linking children's gender and temperament to the quality of their relationships with teachers (Ewing and Taylor, 2009; Hamre and Pianta, 2001; Justice et al., 2008; Liew et al., 2010; Rudasill et al., 2006; Rydell et al., 2005). Abundant evidence suggests boys are more likely to have conflictual teacher-child relationships and girls are more likely to have close teacher-child relationships (e.g., Ewing and Taylor, 2009; Hamre and Pianta, 2001), and findings from the current study were consistent with that. In addition, emerging research indicates children with lower effortful control are more likely to have more conflictual and less close relationships with their teachers (e.g., Liew et al., 2010).

In terms of children's gender, boys received more teacherinitiated interactions than girls, and were also more likely to initiate interactions with teachers. This is consistent with work referenced above regarding relationships between child gender and the frequency of child-initiated interactions in the classroom. Indeed, findings from this study and others suggest that boys receive more interactions from teachers than girls (e.g., Drudy and Chatain, 2002; Younger et al., 1999).

Children who initiated more interactions in third grade were also more likely to have higher closeness ratings from their teachers. This finding is congruent with the Rudasill and RimmKaufman (2009) examination of children and their first grade teachers, and the idea that more interactions between children and teachers would cultivate familiarity between them. Also, children who initiated more interactions in first grade received fewer teacher-initiated interactions in third grade, but more teacher-initiated interactions in first grade were associated with more child- and teacher-initiated interactions in third grade. These longitudinal associations are in contrast to concurrent associations (those within first and third grade) where more childinitiated interactions were associated with more teacher-initiated interactions, but more teacher-initiated interactions were associated with fewer child-initiated interactions.

First grade teacher-child relationships mediated associations between child characteristics and third grade teacherchild relationships. Teacher-child conflict in grade one mediated the relationship between effortful control and third grade conflict, and between gender and third grade conflict. Thus, the fact that children with lower levels of effortful control and boys had more conflict with teachers in third grade may be explained by their greater conflict with teachers in first grade.

Similarly, teacher-child closeness in first grade mediated the relationship between gender and third grade closeness. Here, girls were more likely to have close relationships with third grade teachers, and a mechanism for this association is the fact that girls were also closer with teachers in first grade. These mediated effects suggest that child characteristics are connected to later teacher-child relationships in part through the quality of their relationships in first grade, with early relationship quality establishing patterns for later relationship quality.

The association between child gender and teacher-child conflict in third grade was mediated by the frequency of teacher-initiated interactions in third grade; boys were more likely to receive interactions from teachers, and this was, in turn, positively related to conflict. This finding suggests that a mechanism by which teachers were more likely to rate their relationships with boys as conflictual was their more numerous interactions with boys. This is consistent with work showing that teachers attend more to boys (e.g., Drudy \& Chatain, 2002) and to children who they feel need correction or regulatory control (Dobbs \& Arnold, 2009).

Finally, the number of child-initiated interactions in third grade mediated associations between children's effortful con- 
trol and third grade closeness, and between children's gender and third grade closeness. The finding regarding effortful control is consistent with results with this sample in first grade (Rudasill \& Rimm-Kaufman, 2009) and suggests that one mechanism by which boys and children lower in effortful control (both characteristics that are directly related to lower teacher-child closeness) may be able to cultivate closer relationships with teachers is through their tendency to initiate more interactions with their teachers.

\subsection{Limitations}

Several key limitations to this study should be mentioned. First, participants in the NICHD SECCYD are a relatively ethnically and socioeconomically homogeneous group, primarily representing children from Caucasian and middle class or upper middle class families. Thus, generalizations to diverse groups of children may not be appropriate. Future work examining associations between children's temperament and gender and their interactions and relationships with teachers should include samples with more ethnic and socioeconomic diversity. Second, the correlational nature of this study prevents inferences about causation. Third, assessments of child temperament and teacher-child relationship quality are based on perceptions of parents (for temperament) and teachers (for teacherchild relationship quality), and therefore reflect characteristics of the raters as well as characteristics of the children. Even though parents' and teachers' regular and long-term interactions with children give them unique insight into children's behavior, these assessments would be strengthened with assessments from additional sources (e.g., child report, observations). Fourth, codes for teacher-initiated interactions in first and third grades are slightly different due to changes in coding from first to third grade. Therefore, it is not clear whether codes for teacher-initiated interactions in first and third grades capture the same types of teacher behavior. Fifth, the overall magnitude of effects found in this study is rather small, indicating that there is still much to be explained when understanding teacherchild relationships. Finally, because the estimate of internal reliability for teacher-child closeness in first grade was lower than convention (.64), caution should be exercised when interpreting findings regarding this construct.

\subsection{Implications for early childhood}

Findings reported here are congruent with the study's theoretical foundation that children's early interactions and relationships with teachers are related to their later interactions and relationships with teachers. This study's results add further support for the notion that children's characteristics (i.e., shyness, effortful control, and gender) are related to an important relationship in both first and third grade, either directly or indirectly. Thus, implications for this study are situated within the early elementary school setting. As such, efforts should be made to train preservice and practicing teachers not only about the importance of high quality teacher-child relationships for children's positive academic and social outcomes, but also about the role early teacher-child relationships have in predicting later teacher-child relationships. In addition, training should include emphasis on the ways teacher behavior is related to the quality of this relationship, and how certain child characteristics may place children at risk for poor teacher-child relationships. Taken together, findings from this study suggest that teachers should encourage and facilitate child-initiated interactions in their classrooms, as these may promote teacher-child closeness among children who are more likely to have less closeness in their relationships with teachers. This study focused on the frequency of teacher-child interactions as one mechanism for understanding teacherchild relationship quality. Future research should focus on how the nature of teachers' interactions with children (i.e., are these interactions positive or negative?) may be associated with the quality of their relationships with children.

\section{Conclusions}

Findings from this longitudinal examination from first to third grade point to two overlapping mechanisms that may help explain the quality of children's relationships with teachers. The first is that certain child characteristics seem to directly contribute to the nature of teacher-child relationships. For example, girls in this study had closer relationships with teachers in both first and third grades. It is has been argued elsewhere (Ewing \& Taylor, 2009) that this finding surfaces consistently in teacher-child relationship research because most elementary teachers are female and, therefore, have easier rapport with their female students. The second is that early teacher-child relationship quality and teacher and child behavior establish patterns for later relationship quality and behavior. This is evidenced by the reciprocity between child and teacher behavior both within and across grades, as well as the consistency with which first and third grade teachers rated relationships with children as conflictual and close.

Merging these two mechanisms provides a more comprehensive view of the ways in which child characteristics inform child and teacher behavior, and the ways child and teacher behavior inform teacher perceptions of relationship quality. For example, children higher in effortful control had closer relationships with teachers; however, child-initiated interactions in third grade mediated this effect. Children lower in effortful control initiated more interactions with teachers in third grade, and more interactions with teachers predicted higher ratings of closeness in third grade. This suggests that children's interactions with their teachers may suppress the negative effects of poor effortful control, allowing them to build rapport through frequent contact. Consider another example. Boys were rated by first and third grade teachers as more conflictual, and teacherchild conflict in first grade mediated the association between gender and teacher-child conflict in third grade. This suggests that a mechanism by which boys have conflict with teachers in third grade is their conflict with teachers in earlier grades, thus reinforcing patterns of interaction that persist across years. Both of these examples highlight the complexity of interactions between children and teachers, and how these interactions create and sustain patterns of behavior across time.

In conclusion, this study extends previous work (Rudasill \& Rimm-Kaufman, 2009) by demonstrating that associations between young children's temperament and their interactions and relationships with teachers in first grade continue into third grade. Findings support the notion that children's early teacher-child relationship quality has implications for later teacher-child relationship quality, as well as the idea that quality of these relationships is partly predicated on characteristics of children that are evident in early childhood.

Acknowledgments - This study was conducted by the NICHD Early Child Care Research Network supported by NICHD through a cooperative agreement that calls for scientific collaboration between the grantees and the NICHD staff.

\section{References}

Asendorpf and Meier, 1993 - J. B. Asendorpf and G. H. Meier, Personality effects on children's speech in everyday life: Sociability-mediated exposure 
and shyness-mediated reactivity to social situations, Journal of Personality and Social Psychology 64 (1993), pp. 1072-1083.

Baker, 2006 - J. A. Baker, Contributions of teacher-child relationships to positive school adjustment during elementary school, Journal of School Psychology 44 (2006), pp. 211-229.

Caspi and Silva, 1995 - A. Caspi and P. A. Silva, Temperament qualities at age three predict personality traits in young adulthood: Longitudinal evidence from a birth cohort, Child Development 66 (1995), pp. 486-498.

Coplan and Prakash, 2003 - R. J. Coplan and K. Prakash, Spending time with teacher: Characteristics of preschoolers who frequently elicit versus initiate interactions with teachers, Early Childhood Research Quarterly 18 (2003), pp. 143-158.

Dobbs and Arnold, 2009 - J. Dobbs and D. H. Arnold, Relationship between preschool teachers' reports of children's behavior and their behavior toward those children, School Psychology Quarterly 24 (2009), pp. 95-105.

Drudy and Chatain, 2002 - S. Drudy and M. U. Chatain, Gender effects in classroom interaction: Data collection, self-analysis, and reflection, Evaluation and Research in Education 16 (2002), pp. 34-50.

Eisenhower et al., 2007 - A. S. Eisenhower, B. L. Baker, and J. Blacher, Early student-teacher relationships of children with and without intellectual disability: Contributions of behavioral, social, and self-regulatory competence, Journal of School Psychology 45 (2007), pp. 363-383.

Ewing and Taylor, 2009 • A. R. Ewing and A. R. Taylor, The role of child gender and ethnicity in teacher-child relationship quality and children's behavioral adjustment in preschool, Early Childhood Research Quarterly 24 (2009), pp. 92-105.

Fan et al., 1999 - X. Fan, B. Thompson, and L. Wang, Effects of sample size, estimation methods, and model specification on structural equation modeling fit indexes, Structural Equation Modeling 6 (1999), pp. 56-83.

Hamre and Pianta, 2001 • B. K. Hamre and R. C. Pianta, Early teacher-child relationships and the trajectory of children's school outcomes through eighth grade, Child Development 72 (2001), pp. 625-638.

Hamre and Pianta, 2005 • B. K. Hamre and R. C. Pianta, Can instructional and emotional support in the first-grade classroom make a difference for children at risk of school failure?, Child Development 64 (2005), pp. 949-967.

Howes et al., 2000 • C. Howes, L. C. Phillipsen, and E. Peisner-Feinberg, The consistency of perceived teacher-child relationships between preschool and kindergarten, Journal of School Psychology 38 (2000), pp. 113-132.

Hu and Bentler, 1999 - L. Hu and P. M. Bentler, Cutoff criteria for fit indexes in covariance structure analysis: Conventional criteria versus new alternatives, Structural Equation Modeling 6 (1999), pp. 1-55.

Justice et al., 2008 - L. M. Justice, E. A. Cottone, A. Mashburn, and S. E. Rimm-Kaufman, Relationships between teachers and preschoolers who are at risk: Contribution of children's language skills, temperamentally based attributes, and gender, Early Education and Development 19 (2008), pp. 600-621.

Kagan and Fox, 2006 - J. Kagan and N. Fox, Biology, culture, and temperamental issues (6th ed.). In: W. Damon and N. Eisenberg, editors, Handbook of Child Psychology: Social, Emotional, and Personality Development Vol. 3, Wiley, New York, NY (2006), pp. 167-225.

Kagan et al., 1988 - J. Kagan, J. S. Resnick, N. Snidman, J. Gibbons, and M. O. Johnson, Childhood derivatives of inhibition and lack of inhibition to the unfamiliar, Child Development 59 (1988), pp. 1580-1589.

Kagan et al., 1992 - J. Kagan, N. Snidman, and D. Arcus, Initial reactions to unfamiliarity, Current Directions in Psychological Science 1 (1992), pp. 171-174.

Kagan et al., 1998 - J. Kagan, N. Snidman, and D. Arcus, Childhood derivatives of high and low reactivity in infancy, Child Development 69 (1998), pp. 1483-1493.

Keogh, 2003 - B. Keogh, Temperament in the classroom: Understanding individual differences, Brookes, Baltimore, MD (2003).

Ladd et al., 1999 • G. W. Ladd, S. H. Birch, and E. S. Buhs, Children's social and scholastic lives in kindergarten: Related spheres of influence?, Child Development 70 (1999), pp. 1373-1400.

Liew et al., 2010 - J. Liew, Q. Chen and J. N. Hughes, Child effortful control, teacher-student relationships, and achievement in academically at-risk children: Additive and interactive effects, Early Childhood Research Quarterly 25 (2010), pp. 51-64.

MacKinnon et al., 2007 - D. P. MacKinnon, M. S. Fritz, J. Williams, and C. M. Lockwood, Distribution of the product confidence limits for the indirect effect: Program PRODCLIN, Behavior Research Methods 39 (2007), pp. 384-389.

$\mathrm{O}^{\prime}$ Connor and McCartney, 2006 - E. O'Connor and K. McCartney, Testing associations between young children's relationships with mothers and teachers, Journal of Educational Psychology 98 (2006), pp. 87-98.

O'Connor and McCartney, 2007 - E. O'Connor and K. McCartney, Examining teacher-child relationships and achievement as part of an ecological model of development, American Educational Research Journal 44 (2007), pp. 240-269.

Olson et al., 2005 - S. L. Olson, A. J. Sameroff, D. C. R. Kerr, N. L. Lopez, and H. M. Wellman, Developmental foundations of externalizing problems in young children: The role of effortful control, Development and Psychopa- thology 17 (2005), pp. 25-45

Pianta, 2001 - R. C. Pianta, Student-teacher relationship scale, Psychological Assessment Resources, Inc., Odessa, FL (2001).

Pianta et al., 1995 - R. C. Pianta, M. S. Steinberg and K. B. Rollins, The first two years of school: Teacher-child relationships and deflections in children's classroom adjustment, Development and Psychopathology 7 (1995), pp. 295-312.

Posner and Rothbart, 2000 • M. I. Posner and M. K. Rothbart, Developing mechanisms of self-regulation, Development and Psychopathology 12 (2000), pp. $427-441$.

Rimm-Kaufman and Kagan, 2005 • S. E. Rimm-Kaufman and J. Kagan, Infant predictors of kindergarten behavior: The contribution of inhibited and uninhibited temperament types, Behavioral Disorders 30 (2005), pp. 329-345.

Rimm-Kaufman and Pianta, 2000 • S. E. Rimm-Kaufman and R. C. Pianta, An ecological perspective on the transition to kindergarten: A theoretical framework to guide empirical research, Journal of Applied Developmental Psychology 21 (2000), pp. 491-511.

Rothbart et al., 1994 - M. K. Rothbart, S. A. Ahadi, and K. L. Hershey, Temperament and social behavior in childhood, Merrill-Palmer Quarterly 40 (1994), pp. 21-39.

Rothbart et al., 2001 - M. K. Rothbart, S. A. Ahadi, K. L. Hershey, and P. Fisher, Investigations of temperament at 3 to 7 years: The children's behavioral questionnaire, Child Development 72 (2001), pp. 1394-1408.

Rothbart and Bates, 2006 - M. K. Rothbart and J. E. Bates, Temperament (6th ed.). In: W. Damon and N. Eisenberg, editors, Handbook of Child Psychology: Social, Emotional, and Personality Development Vol. 3, John Wiley \& Sons, Inc., New York (2006), pp. 99-166.

Rothbart et al., 2006 • M. K. Rothbart, M. I. Posner, and J. Kieras, Temperament, attention, and the development of self-regulation. In: K. McCartney and D. Phillips, Editors, Blackwell Handbook of Early Child Development, Blackwell, Malden, MA (2006), pp. 338-357.

Rudasill and Rimm-Kaufman, 2009 - K. M. Rudasill and S. E. RimmKaufman, Teacher-child relationship quality: The roles of child temperament and teacher-child interactions, Early Childhood Research Quarterly 24 (2009), pp. 107-120

Rudasill et al., 2006 • K. M. Rudasill, S. E. Rimm-Kaufman, L. M. Justice, and $\mathrm{K}$. Pence, Temperament and language skills as predictors of teacher-child relationships in preschool, Early Education and Development 17 (2006), pp. 271-291.

Rydell et al., 2005 • A. Rydell, G. Bohlin, and L. B. Thorell, Representations of attachment to parents and shyness as predictors of children's relationships with teachers and peer competence in preschool, Attachment and $\mathrm{Hu}$ man Development 7 (2005), pp. 187-204.

Saft and Pianta, 2001 - E. W. Saft and R. C. Pianta, Teachers' perceptions of their relationships with students: Effects of child age, gender, and ethnicity of teachers and children, School Psychology Quarterly 16 (2001), pp. 125-141.

Sameroff and Fiese, 2000 - A. J. Sameroff and B. H. Fiese, Models of development and developmental risk. In: C. H. Zeanah Jr., editor, Handbook of Infant Mental Health (2nd ed.), Guilford, New York, NY (2000), pp. 3-19.

Sameroff and MacKenzie, 2003 - A. J. Sameroff and M. J. MacKenzie, Research strategies for capturing transactional models of development: The limits of the possible, Development and Psychopathology 15 (2003), pp. 613-640.

She, $2000 \cdot$ H. C. She, The interplay of a biology teacher's beliefs, teaching practices, and gender-based student-teacher classroom interaction, Educational Research 42 (2000), pp. 100-111.

Silver et al., 2005 - R. B. Silver, J. R. Measelle, J. M. Armstrong, and M. J. Essex, Trajectories of classroom externalizing behavior: Contributions of child characteristics, family characteristics, and the teacher-child relationship during the school transition, Journal of School Psychology 43 (2005), pp. $39-60$.

Smith et al., 2007 • F. Smith, F. Hardman, and S. Higgins, Gender inequality in the primary classroom: Will interactive whiteboards help?, Gender and Education 19 (2007), pp. 455-469.

Stuhlman and Pianta, 2001 - M. W. Stuhlman and R. C. Pianta, Teachers' narratives about their relationships with children: Associations with behavior in classrooms, School Psychology Review 31 (2001), pp. 148-163.

Thijs et al., 2008 - J. T. Thijs, H. M. Y. Koomen, and A. Van der Leij, Teacherchild relationships and pedagogical practices: Considering the teacher's perspective, School Psychology Review 37 (2008), pp. 244-260.

Thomas and Chess, 1977 - A. Thomas and S. Chess, Temperament and development, Brunner/Mazel, Oxford, England (1977).

Younger et al., 1999 • M. Younger, M. Warrington and J. Williams, The gender gap and classroom interactions: Reality and rhetoric?, British Journal of Sociology of Education 20 (1999), pp. 325-341.

Zhou et al., 2007 • Q. Zhou, C. Hofer, N. Eisenberg, M. Reiser, T. L. Spinrad, and R. A. Fabes, The developmental trajectories of attentional focusing, attentional and behavioral persistence, and externalizing problems during school-age years, Developmental Psychology 43 (2007), pp. 369-385. 